\title{
Some Optical, Electrical Properties of Lead Free KNN-CZN Ceramics
}

\author{
Phan Dinh Gio*, Truong Thanh Bau, Ngo Vu Hoai, Nguyen Quoc Nam \\ Department of Physics, University of Sciences, Hue University, Hue, Vietnam \\ Email: *pdg_55@yahoo.com
}

How to cite this paper: Gio, P.D., Bau, T.T., Hoai, N.V. and Nam, N.Q. (2020) Some Optical, Electrical Properties of Lead Free KNN-CZN Ceramics. Journal of Materials Science and Chemical Engineering, 8, 1-11.

https://doi.org/10.4236/msce.2020.87001

Received: June 15, 2020

Accepted: July 12, 2020

Published: July 15, 2020

Copyright $\odot 2020$ by author(s) and Scientific Research Publishing Inc. This work is licensed under the Creative Commons Attribution International License (CC BY 4.0).

http://creativecommons.org/licenses/by/4.0/

\begin{abstract}
Lead free $(1-x) \mathrm{K}_{0.5} \mathrm{Na}_{0.5} \mathrm{NbO}_{3}-x \mathrm{Ca}\left(\mathrm{Zn}_{1 / 3} \mathrm{Nb}_{2 / 3}\right) \mathrm{O}_{3}$ (abbreviated $\left.\mathrm{KNN}-\mathrm{xCZN}\right)$ ferroelectric ceramics, with $\mathrm{x}=0,0.02,0.04,0.06,0.08,0.10$, have been fabricated by the conventional solid-state reaction method. The effects of CZN content on the structure, microstructure and some optical, electrical properties of $\mathrm{KNN}-\mathrm{xCZN}$ ceramics were studied in detail. The experimental results showed that the crystal structure of ceramics gradually transformed from orthorhombic phase into pseudo-cubic phase with doping of $x \mathrm{Ca}\left(\mathrm{Zn}_{1 / 3} \mathrm{Nb}_{2 / 3}\right) \mathrm{O}_{3}$. With increasing of the CZN concentration, the ceramic density increased and reached the highest value $\left(4.29 \mathrm{~g} / \mathrm{cm}^{3}\right)$ at $x=0.08 \mathrm{~mol}$, besides, the grain size of the ceramics decreased gradually, the microstructure more uniform, the grains are packed with clear grain boundaries, fewer pores, especially at $x=$ 0.08 mol. With the dense and fine-grained microstructures, the optical transmission of the ceramics is strong, the ceramic sample with $x=0.08 \mathrm{~mol}$ exhibits stably high transmittance above $60 \%$ in the visible spectrum and the largest optical band gap energy $\left(E_{g}=3.0 \mathrm{eV}\right)$ was obtained. The Curie temperature $\left(T_{C}\right)$ decreases when the concentration of CZN increases. The broadness of dielectric peaks around $T_{m}$ indicated a diffusive phase transition for all compositions suggesting the relaxor-like behavior of $\mathrm{KNN}-\mathrm{xCZN}$ ceramic systems.
\end{abstract}

\section{Keywords}

Microstructure, Optical Property, Dielectric, Ferroelectric, KNN-xCZN

\section{Introduction}

Due to environmental pollution caused by lead-containing materials, lead-free piezoceramics have attracted more and more researchers. In recent years, many various lead-free ceramic systems with perovskite structure have been success- 
fully studied [1] [2] [3] [4] [5], among which ( $\mathrm{Na}, \mathrm{K}^{2} \mathrm{NbO}_{3}(\mathrm{KNN})$ based ceramics have attracted a lot of attention due to their strong ferroelectricity, high Curie temperature (about $420^{\circ} \mathrm{C}$ ). With compositional modification by combining $\mathrm{KNN}$ with other perovskite compounds to form KNN-based new solid solutions, such as KNNL [6] [7], KNNLS [8], KNNLST [9], KNNS-BNKZ [10], KNNS-BKZZ [11], the piezoelectric properties of ceramics are further enhanced $\left(\mathrm{d}_{33}>400 \mathrm{pC} / \mathrm{N}\right)$ [12] [13] [14], thereby it has become one of the most promising candidates for replacing Pb-based ceramics in the piezoelectric field. However, most of these studies focused on electrical properties, while the optical properties of the material are rarely mentioned.

As known, lead-free transparent ferroelectric ceramics is a new type of functional material which is friendly to environment, they have great potential in the fields of optoelectronics, infrared detection, lasers and optical storage [15]. Transparent ceramics have been studied since the 1970s on the basis of lead-containing materials such as PLZT [16], PMN-PT [17]. However, due to the toxicity of lead, current studies are focusing on lead-free transparent ferroelectric ceramic materials based on KNN [18], BNKT [19].

This paper presents some research results on structure, microstructure and optical, electrical properties of the lead-free $(1-\mathrm{x}) \mathrm{K}_{0.5} \mathrm{Na}_{0.5} \mathrm{NbO}_{3}-\mathrm{xCa}\left(\mathrm{Zn}_{1 / 3} \mathrm{Nb}_{2 / 3}\right) \mathrm{O}_{3}$ ceramics.

\section{Experimental Procedure}

The $(1-\mathrm{x}) \mathrm{K}_{0.5} \mathrm{Na}_{0.5} \mathrm{NbO}_{3}-\mathrm{xCa}\left(\mathrm{Zn}_{1 / 3} \mathrm{Nb}_{2 / 3}\right) \mathrm{O}_{3}$ (abbreviated $\mathrm{KNN}-\mathrm{xCZN}$ ) ferroelectric ceramics, with $\mathrm{x}=0,0.02,0.04,0.06,0.08$ and 0.1 were synthesized by a conventional mixed-oxide method. The carbonates $\mathrm{K}_{2} \mathrm{CO}_{3}, \mathrm{Na}_{2} \mathrm{CO}_{3}, \mathrm{CaCO}_{3}$ and oxides $\mathrm{Nb}_{2} \mathrm{O}_{5}, \mathrm{ZnO}$ (purity $\geq 99 \%$ ) were used as starting materials. Before being weighed, the $\mathrm{K}_{2} \mathrm{CO}_{3}$ and $\mathrm{Na}_{2} \mathrm{CO}_{3}$ powders were dried in an oven at $150^{\circ} \mathrm{C}$ for 2 hours to minimize the effect of moisture. Mixed powder was milled for 8 hours with the $\mathrm{ZrO}_{2}$ balls in ethanol. The powders were calcined at temperature of $850^{\circ} \mathrm{C}$ for 2 hours to obtain the KNN-CZN compound. Thereafter the calcined powders were ball milled again for 18 hours. The ground materials were pressed into disk $12 \mathrm{~mm}$ in diameter and $1.5 \mathrm{~mm}$ in thick under $1.5 \mathrm{~T} / \mathrm{cm}^{2}$ and then were sintered at temperature of $1130^{\circ} \mathrm{C}$ for 2 hours.

The crystal structure of the ceramic specimens was examined by X-ray diffraction (XRD, D8 ADVANCE) with $\mathrm{CuK}_{\alpha}$ radiation of wavelength $1.5405 \AA$ at room temperature. The microstructure of the specimens was examined by using a scanning electron microscope (SEM) (Hitachi S-4800). The density of specimens was measured by Archimedes method. To measure electrical properties, the ceramic specimens were coated with silver paint on two surfaces and heated at $600^{\circ} \mathrm{C}$ for $15 \mathrm{~min}$. Temperature dependence of dielectric constant and dielectric loss were determined using RLC HIOKI 3532 with automatic programming. The ferroelectric properties were measured by Sawyer-Tower method. The optical transmission spectrum from 200 to $900 \mathrm{~nm}$ was measured by using ultraviolet-visible-near infrared spectroscopy (Genesys 10S UV-Vis (Thermo Scien- 
tific)), the specimens were polished to $0.5 \mathrm{~mm}$ thickness.

\section{Results and Discussion}

\subsection{Structure and Microstructure}

Figure 1(a) shows the XRD patterns were measured in the range of $2 \theta$ from $20^{\circ}$ to $80^{\circ}$ of the KNN-xCZN ceramic specimens sintered at temperature of $1130^{\circ} \mathrm{C}$ for 2 hours. It can be seen that all the ceramics exhibit the coexistence of perovskite phase, no secondary phase was detected. This means that CZN has diffused into the KNN lattice and formed a homogeneous solid solution, in which $\mathrm{Zn}^{2+}(0.74 \AA)$ replaced site of $\mathrm{Nb}^{5+}(0.64 \AA)$ in the octahedral center, and the replacement of $\mathrm{K}^{+}(1.64 \AA)$ and $\mathrm{Na}^{+}(1.39 \AA)$ by $\mathrm{Ca}^{2+}(1.34)$ due to the similarity of the ionic radius [20].

To further determine the effect of CZN doping on the crystalline phase transition of KNN-xCZN ceramics, the X-ray diffraction patterns at $2 \theta \approx 45.5^{\circ}$ of all specimens have been enlarged and simulated using the Gauss fitting function (Figure 1(b)). The simulated data confirm that phase structure of ceramic specimens with $x \leq 0.04$ was orthorhombic perovskite $\mathrm{ABO}_{3}$ type similar to pure $\mathrm{KNN}$ ceramics at room temperature, which is characterized by the double peaks (220) and (020) with a relative intensity ratio of $I_{220} / I_{002}=2 / 1$ [21]. At $X=0.06$, the ceramics showed a mixed orthorhombic and pseudo-cubic phase. As $x$ further increases $(x>0.06)$, the ceramics should be a pseudo-cubic phase as characterized by the single peak $(200)$ at $2 \theta \approx 45.5^{\circ}$. These results are similar to the work of Qizhen Chai et al. [22]. According to the published works [18] [23], the ceramics of symmetrical pseudo-cubic phase generally have the lowest anisotropy, which leads to a decrease in light scattering at the grain boundaries and an increase in optical transmittance.

Table 1 shows density, dielectric constant $\left(\varepsilon_{r}\right)$, dielectric loss $(\tan \delta)$ at the room temperature, Curie temperature $\left(T_{C}\right)$ and the average grain size of $\mathrm{KNN}-\mathrm{xCZN}$ ceramics as a function of the CZN content. As shown, the bulk

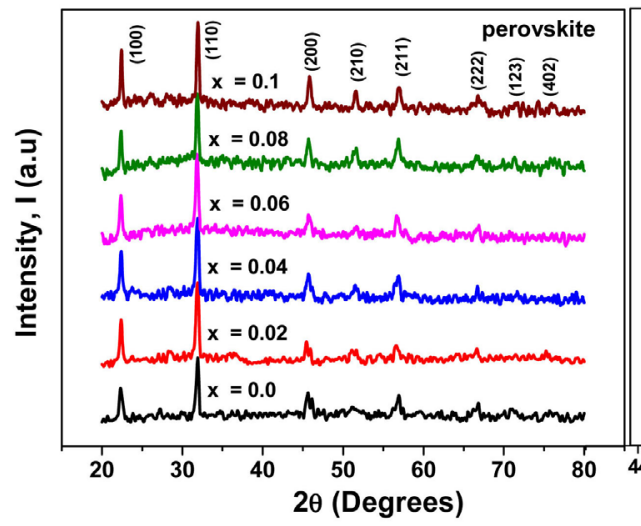

(a)

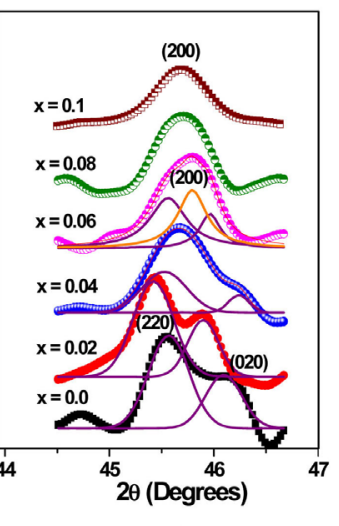

(b)

Figure 1. (a) $\mathrm{XRD}$ patterns of the $(1-x) \mathrm{K}_{0.5} \mathrm{Na}_{0.5} \mathrm{NbO}_{3}-x \mathrm{Ca}\left(\mathrm{Zn}_{1 / 3} \mathrm{Nb}_{2 / 3}\right) \mathrm{O}_{3}$ ceramics with $x=0,0.02,0.04,0.06,0.08$ and 0.1 ; (b) Expanded XRD patterns of the ceramic spcimens at $2 \theta \approx 45.5^{\circ}$ and simulated using the Gauss function. 
Table 1. Relative density $(D)$, dielectric constant $\left(\varepsilon_{r}\right)$, dielectric loss $(\tan \delta)$, Curie temperature $\left(T_{C}\right)$ and mean grain size of the $\mathrm{KNN}$-xCZN ceramics.

\begin{tabular}{cccccc}
\hline $\mathrm{x}$ content $(\mathrm{mol})$ & $D\left(\mathrm{~g} / \mathrm{cm}^{3}\right)$ & $\mathcal{E}_{r}$ & $\tan \delta$ & $T_{C}\left({ }^{\circ} \mathrm{C}\right)$ & Mean grain size $(\mu \mathrm{m})$ \\
\hline 0.0 & 3.64 & 434 & 0.062 & 286 & 3.0 \\
0.02 & 3.82 & 604 & 0.047 & 285 & 2.5 \\
0.04 & 3.84 & 960 & 0.042 & 234 & 1.7 \\
0.06 & 4.06 & 1135 & 0.032 & 199 & 0.8 \\
0.08 & 4.29 & 1334 & 0.01 & 149 & 0.4 \\
0.1 & 4.10 & 1463 & 0.02 & 108 & 1.5 \\
\hline
\end{tabular}

density increased with increasing of $x$ content and reached the highest value $\left(4.29 \mathrm{~g} / \mathrm{cm}^{3}\right)$ at $\mathrm{x}=0.08 \mathrm{~mol}$, then decreased, indicating that with the concentration $\mathrm{x}$ of $0.08 \mathrm{~mol}$, the density of $\mathrm{KNN}-\mathrm{xCZN}$ ceramics is the best. This result is consistent with the microstructure of fracture surfaces of the $\mathrm{KNN}-\mathrm{xCZN}$ ceramics as shown in Figure 2. From Table 1, it can be seen that when the concentration of CZN increases, the room temperature dielectric constant $\left(\mathcal{E}_{\mathrm{r}}\right)$ and dielectric loss $(\tan \delta)$ measured at $10 \mathrm{kHz}$ of $\mathrm{KNN}-\mathrm{xCZN}$ ceramics increased and decreased, respectively. This is explained that the replacement of $\mathrm{K}^{+}(1.64 \AA)$ and $\mathrm{Na}^{+}(1.39 \AA)$ are occupying the A sites of the perovskite lattice by $\mathrm{Ca}^{2+}(1.34 \AA)$ will cause formation of $\mathrm{K}^{+}$and $\mathrm{Na}^{+}$ion vacancies. When two A sites are occupied by two cations with a valence of +2 , a $\mathrm{Na}(\mathrm{K})$ vacancy is created in the lattice to maintain electroneutrality. This result may contribute to the mobility of domain walls, and the dielectric constant is increased and dielectric loss decreased [24].

Figure 2 shows SEM patterns of the fracture surfaces for the KNN-xCZN ceramic specimens sintered at $1130^{\circ} \mathrm{C}$.

As shown in Figure 2, all the ceramic specimens show cubic-like grains, it is characteristic shape of KNN-based materials. The concentration of CZN has strongly influenced on the microstructure of $\mathrm{KNN}-\mathrm{xCZN}$ ceramics, with increasing of CZN doping, the average grain size of ceramics has decreased significantly. The undoped ceramic specimen $(x=0)$ had a porous microstructure, the distribution of discrete grains, corresponding to low density $\left(3.64 \mathrm{~g} / \mathrm{cm}^{3}\right)$, the average size of the grains is abnormally large, $3.0 \mu \mathrm{m}$. However, as seen in Table 1 and Figure 2, when doped CZN with $\mathrm{x} \leq 0.06$, the microstructure of ceramics is gradually improved, the average grain size decreased from $2.5 \mu \mathrm{m}$ to $0.8 \mu \mathrm{m}$, the relatively more uniform grains with cubic shapes; however, there are still some porous holes, maybe this is the reason for low density $\left(\leq 4.06 \mathrm{~g} / \mathrm{cm}^{3}\right)$. Further increasing the CZN content to $0.08 \mathrm{~mol}$, the average grain size of the ceramics decreased to a lowest value $(0.4 \mu \mathrm{m})$, amount of porous decreased markedly, the microstructure of ceramics becomes denser, corresponding to highest density $\left(4.29 \mathrm{~g} / \mathrm{cm}^{3}\right)$. Microstructures with fine grains are an important factor that reduces light scattering and increases the transmittance of the ceramics [23]. When the amount of CZN increases to $0.1 \mathrm{~mol}$, the average grain size of ceramics increases $(1.5 \mu \mathrm{m})$, and porous microstructure. 

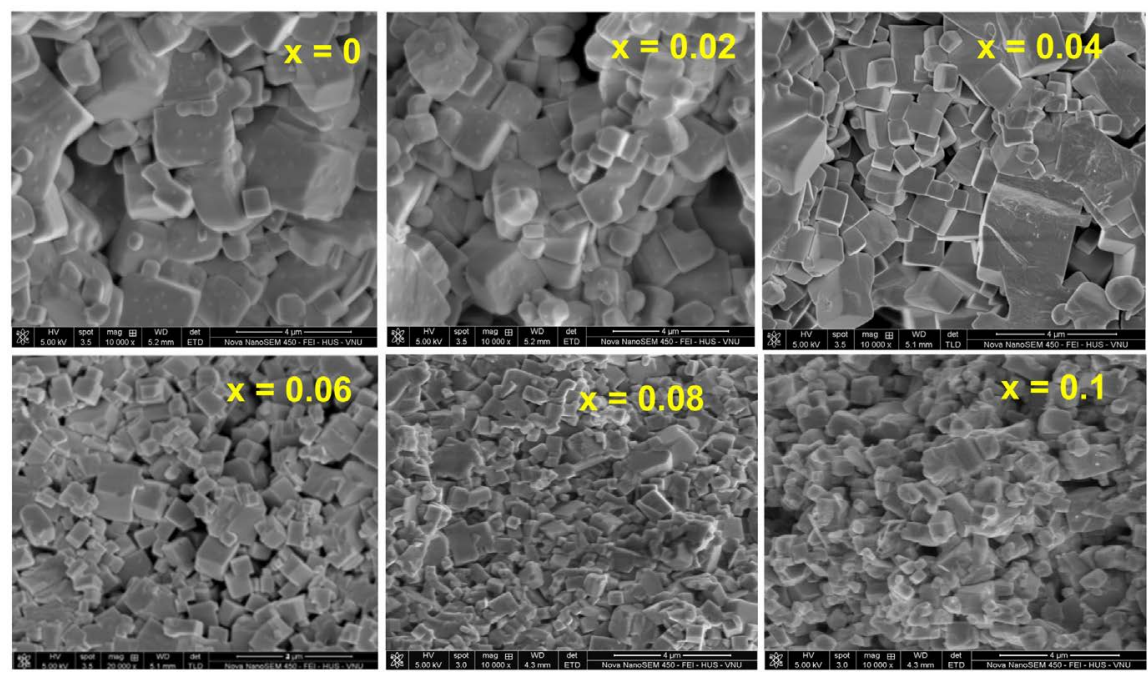

Figure 2. SEM micrographs of KNN-xCZN ceramic specimens with $x=0.0, x=0.02, x=$ $0.04, x=0.06, x=0.08$ and $x=0.1$.

\subsection{Optical Properties}

Figure 3 shows the optical transmittances $(T)$ of the KNN-xCZN ceramic specimens measured in the range of $200-900 \mathrm{~nm}$.

As seen from Figure 3, in the measured wavelength region, the transmittance increases with increasing $x$ from 0 to 0.08 and then decreases when $x=0.1$. The ceramic specimen with $x=0.08$ exhibits high transmittance above $60 \%$ in the visible spectra. For further research of the optical transmission of ceramics, the CZN concentration dependence of optical transmittance of KNN-xCZN for light at wavelength $680 \mathrm{~nm}$ shown in Figure 4. The transmittance increases sharply with increasing of $x$ concentration, reaches a maximum value of $62 \%$ at $x=0.08$ and then decreases. The high transparency of ceramic specimen with concentration $\mathrm{x}$ of 0.08 may be due to fine grain size $(400 \mathrm{~nm})$, low porosity, high crystal structure symmetry (discussed in the previous section) and relaxor behavior (will be mentioned in a later section).

The value of optical band gap energy $\left(E_{g}\right)$ is very important for studies of optical characteristics, which can be calculated from the absorption spectrum using the Tauc equation [25]. For direct transition, the relationship between $E_{g}$ photon frequency $v$ and the absorption coefficient $\alpha$ is given as:

$$
(\alpha h v)^{2}=A\left(h v-E_{g}\right)
$$

where $h$ is Planck's constant $\left(4.1357 \times 10^{-15} \mathrm{eV}\right)$ and $A$ is a constant. The absorption coefficient $\alpha$ is calculated by the formula:

$$
\alpha=\frac{1}{t} \ln \left(\frac{1}{T}\right)
$$

$t$ is the thickness of the sample, $T$ is the transmittance.

The optical band gap energy $\left(E_{g}\right)$ is calculated by plotting $(\alpha h v)^{2}$ versus $h v$ and extrapolating the linear portion of the curve to zero, as shown in Figure 5. 


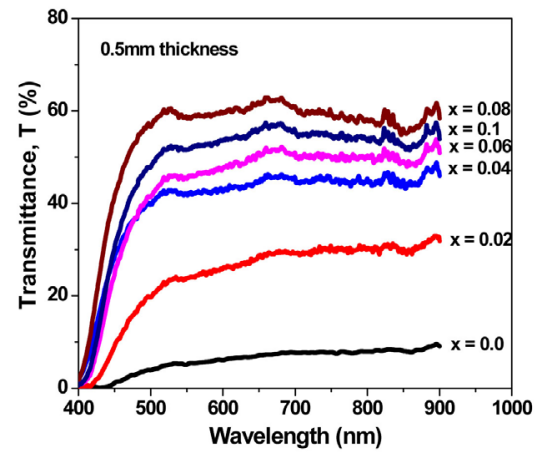

Figure 3. Optical transmittance spectra of the KNN-xCZN transparent ceramics.

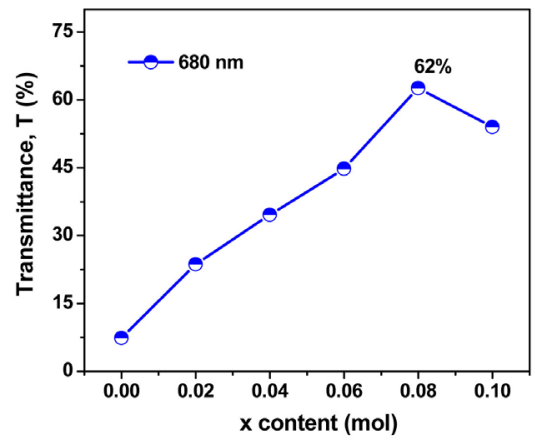

Figure 4. CZN concentration dependence of optical transmittance of KNN-xCZN ceramics measured at wavelength $680 \mathrm{~nm}$.
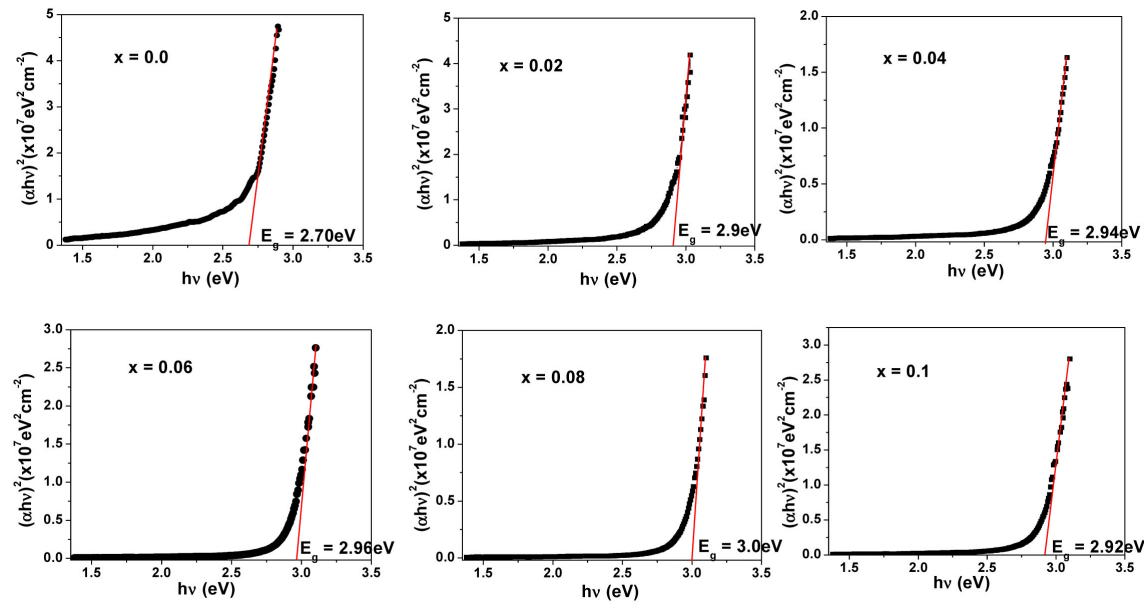

Figure 5. Plot of $(\alpha h v)^{2}$ versus $h v$ and the values of $E_{g}$ for the $\mathrm{KNN}-\mathrm{xCZN}$ transparent ceramics at the different concentrations of CZN.

From the results in Figure 5, x content dependence of $E_{g}$ of $\mathrm{KNN}-\mathrm{xCZN}$ ceramics shown in Figure 6. As seen, with increasing $x$ from 0 to $0.08 \mathrm{~mol}$, the $E_{g}$ band gap energy increases from $2.7 \mathrm{eV}$ at $\mathrm{x}=0$ to a maximum value of $3.0 \mathrm{eV}$ at $\mathrm{x}=0.08$, then decreased, indicating that the doping of CZN has a great influence on the band gap energy of the KNN-xCZN ceramics. Thus, it is obvious that the value of $E_{g}$ is closely related to optical transmission, materials with large $E_{g}$ values will have high optical transparency [22]. 


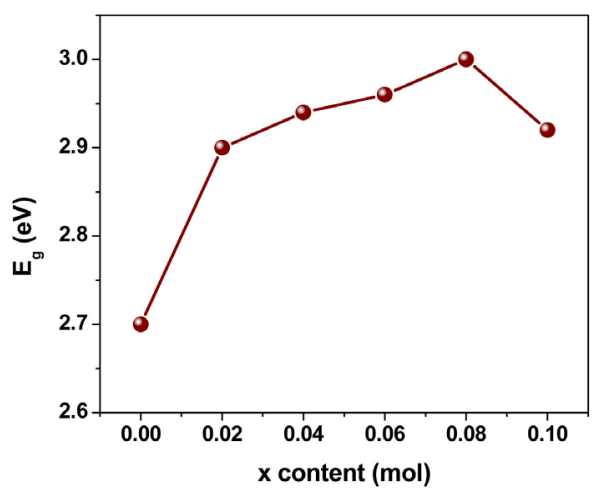

Figure 6. The values of band gap energy $E_{g}$ of KNN-xCZN ceramics at the different $x$ content.

\subsection{Electrical Properties}

Figure 7 shows the temperature dependence of dielectric constant $\varepsilon_{n}$, and dielectric loss $\tan \delta$ measured at $10 \mathrm{kHz}$ frequency in the temperature range of $28^{\circ} \mathrm{C}$ $320^{\circ} \mathrm{C}$ of $\mathrm{KNN}-\mathrm{xCZN}$ ceramics sintered at $1130^{\circ} \mathrm{C}$. As seen, the $(\varepsilon-T)$ curves of the ceramic samples with $x=0,0.02,0.04$ and 0.06 have two obvious peaks: a peak at low temperature, which is the peak corresponding to the ferroelectric phase transition temperatures $T_{O-T}$, however, when $x>0.06$, the $T_{O-T}$ peak is suppressed. The second peak at higher temperatures, corresponding to the ferroelectric-paraelectric phase transition temperature (the $T_{C}$ Curie temperature). While only one dielectric peak $\left(T_{C}\right)$ is observed in the ceramics with $x=0.08$ 0.1 . The $T_{C}$ is significantly dependent on the CZN content and gradually decreases from $285^{\circ} \mathrm{C}$ to $110^{\circ} \mathrm{C}$ as the $\mathrm{x}$ content of CZN increases (the inset Figure 7), this result is related to the structural change of ceramics when the concentration of CZN increases as discussed above. In addition, the results also show that with increasing of $x$ content from 0 to 0.02 , the dielectric peaks of ceramics are still sharp, indicating that the ceramics are a normal ferroelectrics [24], however, when $x \geq 0.04$, the shape of the dielectric peaks became broaden, exhibit the diffuse phase transition, it is one of the characteristics for the relaxor ferroelectrics [24]. Besides, the dielectric loss $\tan \delta$ decreases as the temperature rises from room temperature to $200^{\circ} \mathrm{C}$, and after that the value of $\tan \delta$ increases sharply related to the increased conductivity at high temperature [26].

For the relaxor ferroelectrics, when $T>T_{m}$ (mean value of $T_{C}$ ), the relationship between dielectric constant and temperature obey the Uchino function [27]:

$$
\frac{1}{\varepsilon}-\frac{1}{\varepsilon_{\max }}=\frac{\left(T-T_{m}\right)^{\gamma}}{C}
$$

where, $\varepsilon_{\max }$ is the maximum value of dielectric constant at the phase transition temperature $T_{m}, C$ is the Curie-like constant and $\gamma$ is a diffusion coefficient, with $\gamma=1$ : normal ferroelectrics, $1<\gamma<2$ : relaxor-like ferroelectrics, $\gamma=2$ : ideal relaxor ferroelectrics. The plot of $\ln \left(1 / \mathcal{E}-1 / \mathcal{E}_{\max }\right)$ versus $\ln \left(T-T_{m}\right)$ of $\mathrm{KNN}-\mathrm{xCZN}$ ceramics with $\mathrm{x}$ from 0.04 to 0.1 shown in Figure 8. The results show that these 


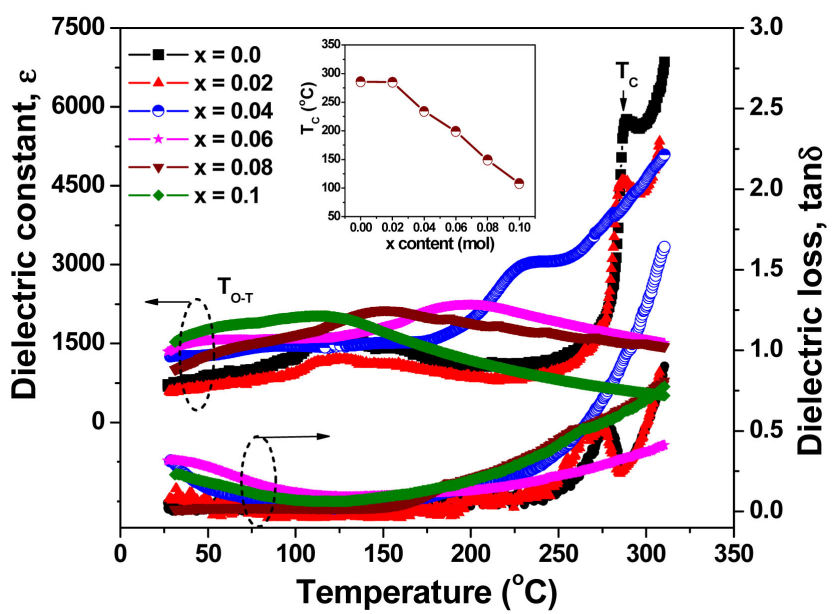

Figure 7. Temperature dependence of dielectric constant $\mathcal{E}$ and dielectric loss $\tan \delta(10$ $\mathrm{kHz}$ ) of the $\mathrm{KNN}^{-} \mathrm{xCZN}$ ceramics measured at $10 \mathrm{kHz}$. The inset is plot of $T_{C}$ versus $x$ content.

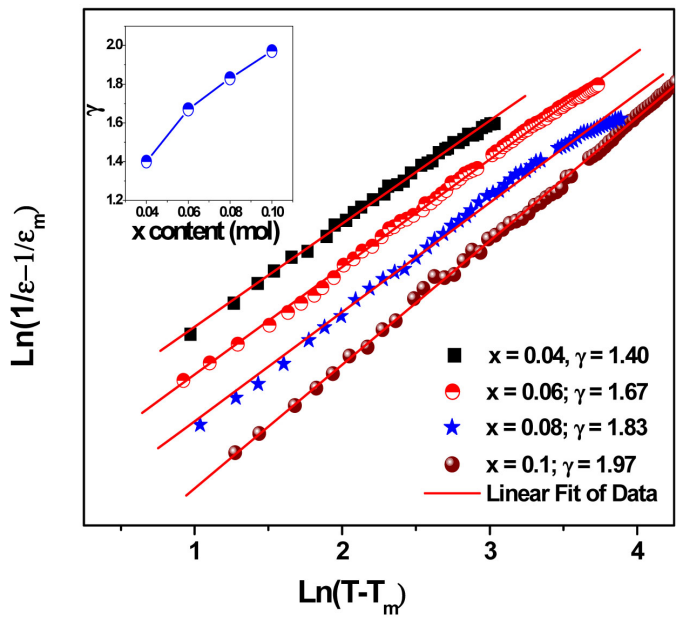

Figure $8 . \ln \left(1 / \mathcal{E}-1 / \varepsilon_{m}\right)$ as a function of $\ln \left(T-T_{m}\right)$ for the $\mathrm{KNN}-\mathrm{xCZN}$ ceramics.

relationships are linear. The slopes of the fitting curves are used to determine the $\gamma$ values. The values of $\gamma$ increased from 1.4 to 1.97 when $x$ content increases from 0.04 to 0.1 , indicating transitions are of diffuse type, which is one of the most important characteristics of relaxor ferroelectrics.

Figure 9 shows the shape of the ferroelectric hysteresis loops of the $\mathrm{KNN}-\mathrm{xCZN}$ ceramic specimens measured at room temperature. As seen, the shape of loop becomes slimmer with increasing of CZN content especially for compositions with $x>0.06$. From the shape of these loops, the remanent polarization $\left(P_{r}\right)$ and the coercive field $\left(E_{C}\right)$ were determined. As shown in Figure 10, with increasing of CZN content from 0 to $0.1 \mathrm{~mol}$, a sharp decrease in $P_{r}$ from 11.4 to $3.3 \mu \mathrm{C} / \mathrm{cm}^{2}$ were observed for ceramics, indicating that the ferroelectric properties are strongly reduced due to the increase of the crystal symmetry from orthorhombic to pseudo-cubic caused by relaxor behavior. Similarly the coercive field $E_{C}$ strong decreased from 9.65 to $5.5 \mathrm{kV} / \mathrm{cm}$. 




Figure 9. Hysteresis loops of $\mathrm{KNN}-\mathrm{xCZN}$ ceramics measured at room temperature.

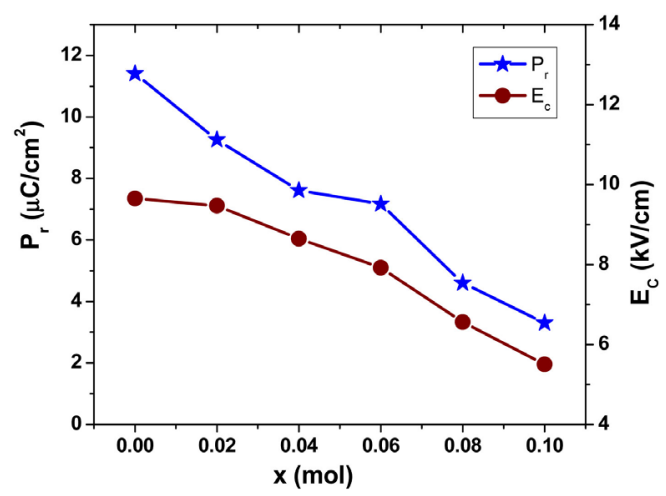

Figure 10. The remnant polarization $\left(P_{\mathrm{r}}\right)$ and coercive field $\left(E_{\mathrm{C}}\right)$ of $\mathrm{KNN}-\mathrm{xCZN}$ ceramics as a function of the CZN content.

\section{Conclusion}

The $(1-x) \mathrm{K}_{0.5} \mathrm{Na}_{0.5} \mathrm{NbO}_{3}-x \mathrm{Ca}\left(\mathrm{Zn}_{1 / 3} \mathrm{Nb}_{2 / 3}\right) \mathrm{O}_{3}(x=0,0.02,0.04,0.06,0.08$ and 0.1$)$ lead-free ferroelectric ceramics were successfully fabricated by conventional sintering method. The effect of CZN addition on the structural phase transition, microstructure and dielectric, ferroelectric properties of ceramics were investigated in detail. The addition of CZN caused an increase in the density and decrease in grain size of ceramics. All samples have perovskite phase structure with a change from orthorhombic $(x \leq 0.04)$ to the orthorhombic-pseudocubic mixed phases at $x=0.06$ and finally the pseudo-cubic phase structure when $x \geq 0.08$. With the dense and fine-grained microstructures, the optical transmission of the ceramics is strong, at $x=0.08 \mathrm{~mol}$ the ceramic exhibits stably high transmittance above $60 \%$ in the visible spectrum and the largest optical band gap energy $\left(E_{g}=\right.$ $3.0 \mathrm{eV})$. The Curie temperature decreased gradually and the shape of the dielectric peaks became broaden with $x \geq 0.04$ indicating a diffusive phase transition for compositions suggesting the relaxor-like behavior of $\mathrm{KNN}-\mathrm{xCZN}$ ceramic systems.

\section{Acknowledgements}

This research is funded by Vietnam National Foundation for Science and Technology Development (NAFOSTED) under grant number 103.02-2019.08. 


\section{Conflicts of Interest}

The authors declare no conflicts of interest regarding the publication of this paper.

\section{References}

[1] Zuo, R.Z., Su, S., Wu, Y., Fu, J., Wang, M. and Li, L.T. (2008) Influence of A-Site Nonstoichiometry on Sintering, Microstructure and Electrical Properties of $\left(\mathrm{Bi}_{0.5} \mathrm{Na}_{0.5}\right) \mathrm{TiO}_{3}$ Ceramics. Materials Chemistry and Physics, 110, 311-315. https://doi.org/10.1016/j.matchemphys.2008.02.007

[2] Bhandari, S., Sinha, N., Raya, G. and Kumar, B. (2014) Processing and Properties of Ferroelectric $\mathrm{Bi}_{0.5}\left(\mathrm{Na}_{0.65} \mathrm{~K}_{0.35}\right)_{0.5} \mathrm{TiO}_{3}$ Ceramics under the Effect of Different Sintering Temperature. Scripta Materialia, 89, 61-64. https://doi.org/10.1016/j.scriptamat.2014.06.029

[3] Wang, K. and Li, J.-F. (2012) (K,Na) $\mathrm{NbO}_{3}$-Based Lead-Free Piezoceramics: Phase Transition, Sintering and Property Enhancement. Journal of Advanced Ceramics, 1 , 24-37. https://doi.org/10.1007/s40145-012-0003-3

[4] Gio, P.D., Viet, H.Q. and Vuong, L.D. (2018) Low-Temperature Sintering of $0.96\left(\mathrm{~K}_{0.5} \mathrm{Na}_{0.5}\right) \mathrm{NbO}_{3}-0.04 \mathrm{LiNbO}_{3}$ Lead-Free Piezoelectric Ceramics Modified with $\mathrm{CuO}$. International Journal of Materials Research, 109, 1071-1076. https://doi.org/10.1166/asem.2019.2364

[5] Karaki, T., Yan, K., Miyamoto, T. and Adachi, M. (2007) Lead-Free Piezoelectric Ceramics with Large Dielectric and Piezoelectric Constants Manufactured from $\mathrm{BaTiO}_{3} \mathrm{Nano}^{-P o w d e r}$. Japanese Journal of Applied Physics, 46, L97-L98. https://doi.org/10.1143/JJAP.46.L97

[6] Gio, P.D. and Lien, N.T.K. (2015) Effect of $\mathrm{LiNbO}_{3}$ on the Structure, Microstructure and Dielectric, Ferroelectric Properties of $\left(\mathrm{K}_{0.5} \mathrm{Na}_{0.5}\right) \mathrm{NbO}_{3}$ Lead Free Ceramics. Indian Journal of Scientific Research and Technology, 3, 48-53.

[7] Matsubara, M., Kikuta, K. and Hirano, S. (2005) Piezoelectric Properties of $\left(\mathrm{K}_{0.5} \mathrm{Na}_{0.5}\right)\left(\mathrm{Nb}_{1-x} \mathrm{Ta}_{x}\right) \mathrm{O}_{3}-\mathrm{K}_{5.4} \mathrm{CuTa}_{10} \mathrm{O}_{29}$ Ceramics. Journal of Applied Physics, 97, Article ID: 114105. https://doi.org/10.1063/1.1926396

[8] Li, H.D., et al. (2007) Effect of Antimony Concentration on the Crystalline Structure, Dielectric, and Piezoelectric Properties of $\left(\mathrm{Na}_{0.5} \mathrm{~K}_{0.5}\right)_{0.945} \mathrm{Li}_{0.055} \mathrm{Nb}_{1-x} \mathrm{Sb}_{x} \mathrm{O}_{3}$ Solid Solutions. Journal of the American Ceramic Society, 90, 3070-3072. https://doi.org/10.1111/j.1551-2916.2007.01875.x

[9] Gio, P.D. and Phong, N.D. (2015) Effects of LiF on the Structure and Electrical Properties of $\left(\mathrm{Na}_{0.52} \mathrm{~K}_{0.435} \mathrm{Li}_{0.045}\right) \mathrm{Nb}_{0.87} \mathrm{Sb}_{0.08} \mathrm{Ta}_{0.05} \mathrm{O}_{3}$ Lead-Free Piezoelectric Ceramics Sintered at Low Temperatures. Journal of Materials Science and Chemical Engineering, 3, 13-20. https://doi.org/10.4236/msce.2015.311003

[10] Tangsritrakul, J. and Hall, D.A. (2017) Structural and Functional Characterisation of KNNS-BNKZ Lead-Free Piezoceramics. Advances in Applied Ceramics, 117, 42-48. https://doi.org/10.1080/17436753.2017.1366733

[11] Wu, J.G. and Wang, Y.M. (2014) Two-Step Sintering of New Potassium Sodium Niobate Ceramics: A High d33 and Wide Sintering Temperature Range. Dalton Transactions, 43, 12836-12841. https://doi.org/10.1039/C4DT01712A

[12] Wang, X.P., Wu, J.G., Xiao, D.Q., Zhu, J.G., Cheng, X.J., Zheng, T., Zhang, B.Y., Lou, X.J. and Wang, X.J. (2014) Giant Piezoelectricity in Potassium-Sodium Niobate Lead-Free Ceramics. Journal of the American Chemical Society, 136, 2905-2910. https://doi.org/10.1021/ja500076h

[13] Cheng, X.J., Wu, J.G., Wang, X.P., Zhang, B.Y., Zhu, J.G., Xiao, D.Q., Wang, X.J., and Lou, X.J. (2013) Giant d33 in $(\mathrm{K}, \mathrm{Na})(\mathrm{Nb}, \mathrm{Sb}) \mathrm{O}_{3}-(\mathrm{Bi}, \mathrm{Na}, \mathrm{K}, \mathrm{Li}) \mathrm{ZrO}_{3}$ Based Lead-Free 
Piezoelectrics with High Tc. Applied Physics Letters, 103, Article ID: 052906. https://doi.org/10.1063/1.4817517

[14] Saito, Y., Takao, H., Tani, T., Nonoyama, T., Takatori, K., Homma, Nagoya, T. and Nakamura, M. (2004) Lead-Free Piezoceramics. Nature, 432, 84-87.

https://doi.org/10.1038/nature03028

[15] Geng, Z.M., Li, K., Shi, D.L., Zhang, L.L. and Shi, X.Y. (2015) Effect of Sr and Ba-Doping in Optical and Electrical Properties of KNN Based Transparent Ceramics. Journal of Materials Science: Materials in Electronics, 26, 6769-6775. https://doi.org/10.1007/s10854-015-3287-6

[16] Haertling, G.H. (1999) Ferroelectric Ceramics: History and Technology. Journal of the American Ceramic Society, 82, 797-818. https://doi.org/10.1111/j.1151-2916.1999.tb01840.x

[17] Fujii, I., Yoshida, R., Imai, T., Yamazoe, S. and Wada, T. (2013) Fabrication of Transparent $\mathrm{Pb}\left(\mathrm{Mg}_{1 / 3} \mathrm{Nb}_{2 / 3}\right) \mathrm{O}_{3}-\mathrm{PbTiO}_{3}$ Based Ceramics by Conventional Sintering. Journal of the European Ceramic Society, 96, 3782-3787. https://doi.org/10.1111/jace.12574

[18] Chai, Q.Z., Yang, D., Zhao, X.M., Chao, X.L. and Yang, Z.P. (2018) Lead-Free $(\mathrm{K}, \mathrm{Na}) \mathrm{NbO}_{3}$-Based Ceramics with High Optical Transparency and Large Energy Storage Ability. Journal of the American Ceramic Society, 101, 2321-2329. https://doi.org/10.1111/jace.15392

[19] Quan, N.D., Quyet, N.V., Bac, L.H., Thiet, D.V., Hung, V.N. and Dung, D.D. (2015) Structural, Ferroelectric, Optical Properties of A-Site-Modified $\mathrm{Bi}_{0.5}\left(\mathrm{Na}_{0.78} \mathrm{~K}_{0.22}\right)_{0.5}$ $\mathrm{Ti}_{0.97} \mathrm{Zr}_{0.03} \mathrm{O}_{3}$ Lead-Free Piezoceramics. Journal of Physics and Chemistry of Solids, 77, 62-67. https://doi.org/10.1016/j.jpcs.2014.10.010

[20] Yang, D., Ma, C., Yang, Z., Wei, L., Chao, X., Yang, Z. and Yang, J. (2016) Optical and Electrical Properties of Pressureless Sintered Transparent $\left(\mathrm{K}_{0.37} \mathrm{Na}_{0.63}\right) \mathrm{NbO}_{3}-$ Based Ceramics. Ceramics International, 42, 4648-4657. https://doi.org/10.1016/j.ceramint.2015.11.032

[21] Yao, F.-Z., Patterson, E.A., Wang, K., Jo, W., Rodel, J. and Li, J.-F. (2014) Enhanced Bipolar Fatigue Resistance in $\mathrm{CaZrO}_{3}$-Modified $(\mathrm{K}, \mathrm{Na}) \mathrm{NbO}_{3}$ Lead-Free Piezoceramics. Applied Physics Letters, 104, Article ID: 242912. https://doi.org/10.1063/1.4884826

[22] Chai, Q.Z., Zhao, X.M., Chao, X.L. and Yang, Z.P. (2017) Enhanced Transmittance and Piezoelectricity of Transparent $\mathrm{K}_{0.5} \mathrm{Na}_{0.5} \mathrm{NbO}_{3}$ Ceramics with $\mathrm{Ca}\left(\mathrm{Zn}_{1 / 3} \mathrm{Nb}_{2 / 3}\right) \mathrm{O}_{3}$ Additives. RSC Advances, 7, 28428-28437. https://doi.org/10.1039/C7RA04064D

[23] Zhang, X., Yang, D., Yang, Z., Zhao, X., Chai, Q., Chao, X., Yang, Z., et al. (2016) Transparency of $\mathrm{K}_{0.5} \mathrm{~N}_{0.5} \mathrm{NbO}_{3}-\mathrm{Sr}\left(\mathrm{Mg}_{1 / 3} \mathrm{Nb}_{2 / 3}\right) \mathrm{O}_{3}$ Lead-Free Ceramics Modulated by Relaxor Behavior and Grain Size. Ceramics International, 42, 17963-17971. https://doi.org/10.1016/j.ceramint.2016.07.069

[24] Xu, Y.H. (1991) Ferroelectric Materials and Their Applications. North-Holland, Amsterdam.

[25] Tauc, J. and Wood, D.L. (1972) Weak Absorption Tails in Amorphous Semiconductors. Physical Review B, 5, 3144-3151. https://doi.org/10.1103/PhysRevB.5.3144

[26] Liu, B.H., Zhang, Y., Li, P., Shen, B. and Zhai, J.W. (2016) Phase Transition and Electrical Properties of $\mathrm{Bi}_{0.5}\left(\mathrm{Na}_{0.8} \mathrm{~K}_{0.2}\right)_{0.5} \mathrm{ZrO}_{3}$ Modified $\left(\mathrm{K}_{0.52} \mathrm{Na}_{0.48}\right)\left(\mathrm{Nb}_{0.95} \mathrm{Sb}_{0.05}\right) \mathrm{O}_{3}$ Lead-Free Piezoelectric Ceramics. Ceramics International, 42, 13824-13829. https://doi.org/10.1016/j.ceramint.2016.05.186

[27] Uchino, K. (1991) Relaxor Ferroelectrics. Journal of the Ceramic Society of Japan, 99, 829-835. https://doi.org/10.2109/jcersj.99.829 